\title{
SCIENTIFIC REP RTS OPEN Sulfur isotopes ratio of atmospheric
carbonyl sulfide constrains its
sources
}

Received: 19 October 2018

Accepted: 4 December 2018

Published online: 24 January 2019

\author{
Alon Angert $(\mathbb{D}$, Ward Said-Ahmad, Chen Davidson \& Alon Amrani
}

Carbonyl sulfide (COS) is the major long-lived sulfur bearing gas in the atmosphere, and is used to estimate the rates of regional and global (both past and current) photosynthesis. Sulfur isotope measurements $\left({ }^{34} \mathrm{~S} /{ }^{32} \mathrm{~S}\right.$ ratio, $\left.\delta^{34} \mathrm{~S}\right)$ of $\operatorname{COS}$ may offer a way for improved determinations of atmospheric $\operatorname{COS}$ sources. However, measuring the $\operatorname{COS} \delta^{34} \mathrm{~S}$ at the atmospheric concentrations of $\sim 0.5 \mathrm{ppb}$ is challenging. Here we present high-accuracy $\delta^{34} S$ measurements of atmospheric $\operatorname{COS}$ done by gas chromatograph (GC) connected to a multicollector inductively coupled plasma mass spectrometer (MC-ICPMS), after pre-concentrating from 2-liters of air. We showed that the precision of $\cos \delta^{34} \mathrm{~S}$ measurement for gas standards is $\leq 0.2 \%$, and that $\mathrm{N}_{2}$ and $\mathrm{CO}_{2}$ in the gas standard mixture had no effect on the measured $\delta^{34} \mathrm{~S}$. Natural air samples were collected in Israel and in the Canary Islands. The $\cos \delta^{34} S$ values in both locations were found to be $13.2 \pm 0.6 \%$, and are believed to represent the background tropospheric value. This $\delta^{34} \mathrm{~S}$ value is markedly different from the previously reported value of $4.9 \%$. We estimate the expected isotopic signature of COS sources and sinks, and use the $\delta^{34} S$ value of atmospheric $\operatorname{COS}$ we measured to estimate that $\sim 48 \%$ of it originates from the ocean.

The atmosphere contains about $0.5 \mathrm{ppb}$ carbonyl sulfide (COS), with a lifetime of few years ${ }^{1}$. Because it is relatively long-lived, the COS is hypothesized to be a large source of background stratospheric aerosols which have important control on Earth albedo and stratospheric chemistry, including the ozone layer ${ }^{2,3}$. In addition, since COS follows a similar pathway to $\mathrm{CO}_{2}$ through stomata during photosynthesis, it can be used to estimate the photosynthesis rates, mainly on a global scale for both the present and for the last centur $y^{4-7}$, but also on regional scale $^{8}$. The main natural source of COS to the atmosphere is the ocean, both as direct COS emission, and indirect as carbon disulfide $\left(\mathrm{CS}_{2}\right)$ and dimetheylsulfide (DMS) emissions that rapidly oxidized to $\mathrm{COS}^{9}$. Anthropogenic sources of COS are dominated by indirect sources $\left(\mathrm{CS}_{2}\right)$ and include rayon production, aluminum production, coal combustion, biomass burning, oil refineries and fuel combustion ${ }^{10,11}$.

The relatively small decadal trends in COS atmospheric concentrations indicate that on a global scale, the sources and sinks are approximately balanced. A recent review of the atmosphere COS budget ${ }^{12}$ highlights the major knowledge gaps. Previous studies also demonstrated the large uncertainty in the global COS budget, with 3 -fold uncertainty in plant uptake ${ }^{4}$ and up to 8 -fold uncertainty in the ocean source ${ }^{13}$ and 3 -fold uncertainty in the anthropogenic COS sources ${ }^{5}$. The uncertainties in ocean COS emissions are related in part to the physicochemical and biogeochemical models that are used for these estimations, and the scarcity of direct measurements ${ }^{13,14}$.

Sulfur isotope measurements $\left({ }^{34} \mathrm{~S} /{ }^{32} \mathrm{~S}\right.$ ratio, $\left.\delta^{34} \mathrm{~S}\right)$ of COS are suggested here as a novel approach for the determinations of atmospheric COS sources. The isotopic approach assumes that COS sources (mainly oceanic and anthropogenic, but also biomass burning and soil) have distinct $\delta^{34} S$ values. Therefore, the contribution of each COS source to the atmosphere can be calculated using the appropriate isotope mass balance equations, and knowledge on the fractionation during uptake by the sinks (mainly plants, but also atmospheric oxidation and soils). The isotopic mass balance, assuming steady state since the long-term trends are small ${ }^{7}$, can be presented by the following equation:

$$
\begin{aligned}
& \mathrm{O} \times \delta^{34} \mathrm{~S}_{\text {COS-ocean }}+\mathrm{A} \times \delta^{34} \mathrm{~S}_{\text {COS-anthropogenic }}=\mathrm{P} \times\left(\delta^{34} \mathrm{~S}_{\text {COS-atmosphere }}+\varepsilon_{\mathrm{p}}\right) \\
& +\mathrm{S} \times\left(\delta^{34} \mathrm{~S}_{\text {COS-atmosphere }}+\varepsilon_{\mathrm{s}}\right)+\mathrm{X} \times\left(\delta^{34} \mathrm{~S}_{\text {COS-atmosphere }}+\varepsilon_{\mathrm{x}}\right)
\end{aligned}
$$

The Institute of Earth Sciences, The Hebrew University of Jerusalem, Jerusalem, Israel. Correspondence and requests for materials should be addressed to A.A. (email: alon.amrani@mail.huji.ac.il) 
The left side of the equation represents the sources and their isotopic composition: $\mathrm{O}$ is the flux from the ocean (combined direct and indirect fluxes), $\delta^{34} \mathrm{~S}_{\mathrm{COS} \text {-ocean }}$ is the average weighted ocean source isotopic composition, $\mathrm{A}$ is the anthropogenic flux, and $\delta^{34} S_{\text {COS-anthropogenic }}$ is its average isotopic composition. The right side represents the sinks, where $\mathrm{P}, \mathrm{S}$, and $\mathrm{X}$ are the sinks by plant, soil, and atmospheric oxidation, respectively. The possible fractionations during uptake are represented by $\varepsilon$ with the corresponding subscript. Estimating the relative contributions of the sources to atmospheric COS will provide an important constraint to the COS budget and photosynthesis models, and thus reduce their uncertainties.

Measurements of sulfur isotopes in atmospheric COS are challenging because of its low concentrations: $\sim 0.5 \mathrm{ppb}$. A recent method of $\operatorname{COS} \delta^{34} \mathrm{~S}$ analysis on fragments ions using a pre-concentration air system coupled with isotope ratio mass spectrometer (IRMS) requires 10's nmol which translates to hundreds of liters of air per analysis ${ }^{15}$. With this method these researchers were able to provide a single $\delta^{34} S$ value of COS of a compressed air sample from one location in Japan (Kawasaki). However, the need for hundreds of liters of air per analysis still limits the applicability of this method.

A more tractable analytical approach for the analysis of trace atmospheric sulfur compounds is the coupling of a gas chromatograph (GC) with a multicollector inductively coupled plasma mass spectrometer (MC-ICPMS) ${ }^{16}$. This method enables the measurements of $\delta^{34} S$ values in individual volatile and gas compounds and requires a sample size of the pmol level or about $10^{4}$-fold lower than that of a regular IRMS ${ }^{16-18}$. The current sensitivity of the GC/MC-ICPMS required only 1-2 L of air for reliable $\delta^{34} S$ analysis of atmospheric COS. Here we use the GC/MC-ICPMS for accurate and precise $\delta^{34} S$ determination of COS in low volumes of atmospheric air in two locations.

\section{Results}

Precision and accuracy of $\operatorname{COS} \delta^{34} \mathrm{~S}$ analysis at low concentrations. The method we used was a combination and modification of two existing methods. One is the Tenax resin pre-concentration of COS from air ${ }^{15,19}$ and the second is the $\delta^{34} S$ analysis of gases using GC/MC-ICPMS ${ }^{18}$. To ensure that our method preserves the original $\delta^{34} S$ value of the measured COS, we have measured the following COS standards using two introduction methods, direct injection and pre-concentration. These gas mixtures were calibrated against Mix 1 that contained several sulfur compounds including COS at concentration of $\sim 21 \mathrm{ppm}$. The COS main standard (4.7\% in He, hereafter "Mix 2") was diluted and mixed with other gases to make additional 2 mixtures: a 5.2 ppm of COS in $\mathrm{He}$ (99.995\% pure) hereafter "Mix 3", and $1.7 \mathrm{ppb} \mathrm{COS}$, diluted in $\sim 500 \mathrm{ppm} \mathrm{CO}_{2}$ and $\mathrm{N}_{2}$ as balance, hereafter "Mix 4". The $\mathrm{N}_{2}$ was added to the mixture to verify successful capture of COS on Tenax when diluted by the main component of the atmosphere. $\mathrm{CO}_{2}$ was added since it condenses in the Tenax trap temperature $\left(-90^{\circ} \mathrm{C}\right)$, and thus can potentially interfere. Note that both $\mathrm{N}_{2}$ and $\mathrm{O}_{2}$ do not spontaneously react with COS, nor will it react with the Tenax at this temperature. Other gases are not expected to interfere in COS trapping on Tenax because they are in trace amounts in the atmosphere, and even if captured by the Tenax, they will be separated by the GC column.

Standards mixtures 2-4 have the same original COS gas which was isotopically calibrated against our laboratory standards. The first standard (Mix 2) was measured directly, without the pre-concentration system. The second standard (Mix 3) was measured both directly and by the pre-concentration system. And Mix 4 was measured only by the pre-concentration system (Fig. 1, Table 1). Hence, measuring these standards tests for possible fractionation during pre-concentration, and for possible interference by $\mathrm{N}_{2}$ and $\mathrm{CO}_{2}$ during capture on the Tenax resin. Table 1 summarize the results of these tests. The results show that there is no fractionation involved with the pre-concentration step, even when $\mathrm{N}_{2}$ and $\mathrm{CO}_{2}$ are present. In addition, for the Mix 3 standard that was measured both by pre-concentration and by direct injection to the GC, we found that the yield of the pre-concentration system is better than $97 \%$.

Analysis of natural air samples. Air was sampled in Jerusalem, Israel $\left(31^{\circ} 46^{\prime} 12^{\prime \prime} \mathrm{N} / 35^{\circ} 11^{\prime} 51^{\prime \prime} \mathrm{E}\right)$ in August and October 2017 and March 2018, and in the Canary Island of Fuerteventura $\left(28^{\circ} 43^{\prime} 30^{\prime \prime} \mathrm{N} / 13^{\circ} 50^{\prime} 33^{\prime \prime} \mathrm{W}\right)$ in February 2018. To check the stability and precision of air measurements of COS in air samples using Sulfinert 2.25 L cylinders (see Methods section), we have measured 9 air samples next to the institute of Earth Sciences in the Hebrew University, Jerusalem, during August and October 2017. The results are presented in Table 2 (all the $\delta^{34} \mathrm{~S}$ values in this work are reported against VCDT). The average $\delta^{34} \mathrm{~S}$ value for these measurements set was $13.4 \pm 0.5 \%$ o (std, $1 \sigma$ ), which demonstrates the stability and precision of the system over time. The higher errors compared to the standard measurements are most probably introduced by COS blanks left in the sampling cylinders after the cleaning procedure. It is possible that an improved cleaning procedure (e.g. repeating all the steps twice) will lower this blank. The RSD (Relative Standard Deviation) of the peak area is $10.4 \%$, which represents the variability in the MC-ICPMS sensitivity, which was not corrected against a COS concertation standard in this first campaign. We have performed two more sampling campaigns using a different method of sampling (electropolished canisters, see Methods) during February and March 2018 to check for a possible difference in COS $\delta^{34} \mathrm{~S}$ values that arise from geographic location. Table 2 details the location, COS concentration and isotopic composition of each sampling campaign. There was no apparent difference in $\delta^{34} S$ values between samples taken in Sulfinert treated stainless steel cylinders, and those taken with electropolished stainless steel canisters, indicating that both are acceptable options for COS sampling. The measurements of air sampled resulted in an average $( \pm 1 \sigma$ std) concentration of $0.52 \pm 0.01 \mathrm{ppb}$ for the two sites. This concertation agrees well with the known concertation of COS in the atmosphere, and thus indicate good preservation of the samples during the few weeks from sampling to analysis. The average $\delta^{34} S$ value $( \pm 1 \sigma$ std) for the February-March campaign was found to be $12.8 \pm 0.5 \%$ $(\mathrm{n}=3)$ for Jerusalem, and $13.1 \pm 0.7 \% 0(\mathrm{n}=3)$ for the Canary Islands. The overall average for all months and both location is $13.2 \pm 0.6 \%$ o (with no significant temporal or spatial variation). 


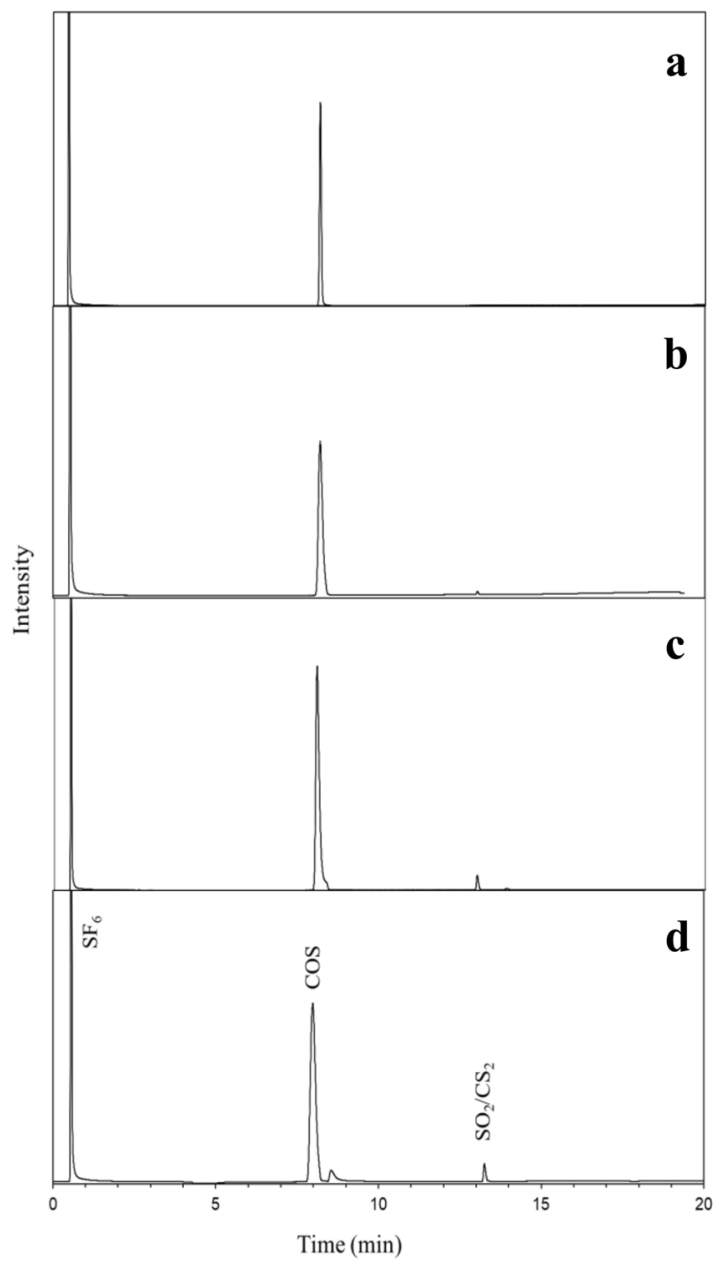

Figure 1. Chromatogram produced by the GC/MC-ICPMS system for the injection of (a). $5.2 \mathrm{ppm}$ COS standard by direct injection (b). $5.2 \mathrm{ppm}$ COS standard by pre-concentration system (c). $1.7 \mathrm{ppb}$ COS standard by pre-concentration system $(\mathbf{d})$. Air sample by the pre-concentration system. The $\mathrm{SF}_{6}$ peaks are used as internal standards in each chromatogram and are calibrated every 3-4 samples by known standards as detailed in the Methods section.

\begin{tabular}{|c|c|c|c|c|c|c|c|c|}
\hline Standard & Balance & Conc. & & $\begin{array}{l}\text { Amount } \\
\text { measured }\end{array}$ & $\begin{array}{l}\text { Amount RSD } \\
\text { error }\end{array}$ & $\delta^{34} S$ & Error & Repetitions \\
\hline mix \# & gas & $(\mathrm{mol} / \mathrm{mol})$ & Method & pmol & $\%$ & $\%$ & std & $\mathbf{n}$ \\
\hline 2 & $\mathrm{He}$ & $4.70 \%$ & direct injection ${ }^{1}$ & 265 & 1.7 & -6.2 & 0.1 & 5 \\
\hline 3 & $\mathrm{He}$ & $5.2 \mathrm{ppm}$ & direct injection & 20 & 2.8 & -6.0 & 0.2 & 17 \\
\hline 3 & $\mathrm{He}$ & $5.2 \mathrm{ppm}$ & pre-conc. & 20 & 2.0 & -6.1 & 0.0 & 3 \\
\hline 4 & $\mathrm{~N}_{2}+\mathrm{CO}_{2}$ & $1.7 \mathrm{ppb}$ & pre-conc. & 65 & 3.0 & -6.0 & 0.1 & 4 \\
\hline
\end{tabular}

Table 1. Results of GC/MC-ICPMS analysis of COS standards.

\section{Discussion}

Our COS standards analysis showed that the method we used is highly useful and applicable for measurements of $\operatorname{COS} \delta^{34} S$ values at atmospheric concentrations. There were no apparent effects of the pre-concentration step on the precision and accuracy, and no interfering effects from other gases in the gas matrix used (either $\mathrm{He}$ or $\mathrm{N}_{2}$ and $\mathrm{CO}_{2}$ ). These results provide confidence that the measurements of natural air samples represent reliably the atmospheric $\operatorname{COS} \delta^{34} S$ values.

The natural air samples showed an average $\delta^{34} S$ value of $13.2 \pm 0.6 \%$, with no detectable variation in isotopic composition between the Canary Islands and Israel, despite a very different trajectory of the air before arriving to the sampling locations. A back-trajectory analysis by NOAA's HYSPLIT ${ }^{20}$ shows that the history of the air sampled in the Canary Islands was mostly of a path along the north Atlantic, which only slightly brushed against the western edge of Europe (mostly Portugal), before continuing over the Atlantic to the sampling point. In contrast, the air sampled in Israel had a much more continental path (Fig. 2). The similar values for Israel and the Canary 


\begin{tabular}{|c|c|c|c|c|c|c|}
\hline \multirow[b]{2}{*}{ Air sample } & \multirow{2}{*}{$\begin{array}{l}\text { Amount } \\
\text { pmol }\end{array}$} & \multirow{2}{*}{$\begin{array}{l}\text { Conc. } \\
\text { ppt }\end{array}$} & $\begin{array}{l}\text { Conc. } \\
\text { error }\end{array}$ & \multirow{2}{*}{$\delta^{34} \mathrm{~S} \%$} & \multirow{2}{*}{\begin{tabular}{|l|}
$\delta^{34}$ S error \\
Std \%o
\end{tabular}} & \multirow{2}{*}{\begin{tabular}{|l} 
Repetition \\
$\mathbf{n}$
\end{tabular}} \\
\hline & & & RSD $\%$ & & & \\
\hline Israel 1 & 28 & - & 10.4 & \begin{tabular}{|l|}
13.4 \\
\end{tabular} & 0.5 & 9 \\
\hline Israel 2 & 38 & 502 & 6.6 & 12.8 & 0.5 & 3 \\
\hline Canary Islands & 45 & 533 & 7.5 & 13.1 & 0.7 & 3 \\
\hline
\end{tabular}

Table 2. Results of GC/MC-ICPMS analysis of COS in air samples from Israel and the Canary Island. Israel 1 -samples were taken by Sulfinert cylinders in Israel at the Institute of Earth Science, The Hebrew University of Jerusalem $\left(31^{\circ} 46^{\prime} 12^{\prime \prime} \mathrm{N} / 35^{\circ} 11^{\prime} 52^{\prime \prime} \mathrm{E}\right)$. Israel 2 - samples were taken by electropolished canisters in Israel at the Institute of Earth Science, The Hebrew University of Jerusalem $\left(31^{\circ} 46^{\prime} 12^{\prime \prime} \mathrm{N} / 35^{\circ} 11^{\prime} 52^{\prime \prime} \mathrm{E}\right)$. Canary Islands - samples were taken by electropolished canisters in the Canary Islands at Punta de Tivas, Fuerteventura island $\left(28^{\circ} 43^{\prime} 30^{\prime \prime} \mathrm{N} / 13^{\circ} 50^{\prime} 33^{\prime \prime} \mathrm{W}\right)$.
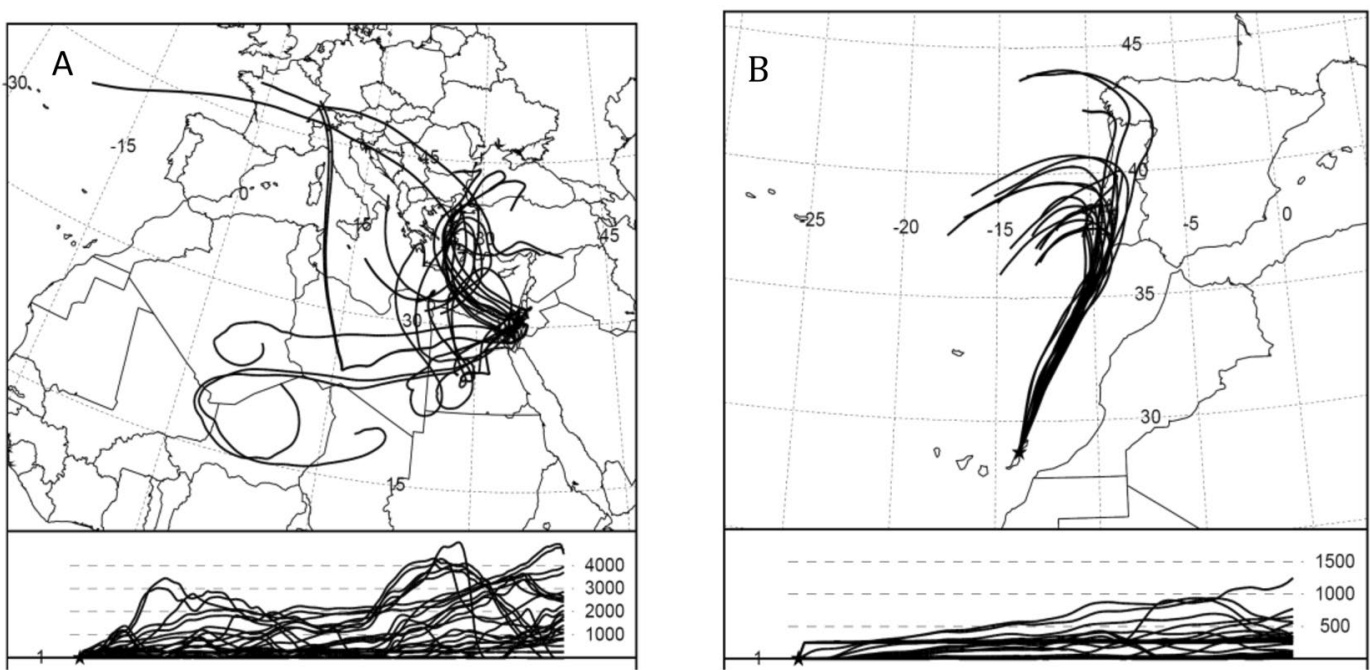

Figure 2. Back trajectories for 10 days (produced by NOAA HYSPLIT MODEL ${ }^{20}$ ) of the air before arriving to the air sampling locations during Feburary and March 2018: (A) Israel, (B) Canary Islands.

Islands are probably the result of the long life time of COS in the atmosphere, which is a few years ${ }^{1}$. Hence, this similarity seems to indicate that the $\delta^{34} S$ value we measured represents the clean atmosphere.

The only previously published measurement of atmospheric $\operatorname{COS}^{15}$ reported a measurement of a single sample with $\delta^{34} S$ value of $4.9 \pm 0.3 \%$. This value is much lighter from an estimated ${ }^{21}$ value of $11 \%$, and from the value we measured $(13.2 \pm 0.6 \%$ o $)$ in two independent locations. This mismatch may stem from the fact that Hattori et al. ${ }^{15}$ single $\delta^{34} S$ value was measured from compressed air that was collected at the manufacturer's factory in Kawasaki, Japan, and might not represent the clean atmosphere COS signal. It might also result from the markedly different methods used in the two studies. More specifically, the need to pre-concentrate hundreds of liters of air in Hattori et al. ${ }^{15}$ as well as the analysis on fragments ions may introduce additional sources of error. However, although it seems unlikely, we cannot rule out at this stage the possibility that the $\delta^{34} S$ value of COS is not homogenous globally and so there are real and significant difference between the $\delta^{34} S$ values between Japan and Israel/Canary Islands. Further $\delta^{34} S$ analyses of COS from around the world are needed to confirm that.

Assuming that the atmosphere is well mixed (homogenous) in regards to COS, and using our clean air atmospheric $\operatorname{COS} \delta^{34} S$ value (i.e. $13.2 \pm 0.6 \%$ ) to represent it, there are several important implications that can be drawn in relation to the contribution of COS to background aerosols and to the relative sources of COS to the atmosphere.

COS is suggested to be an important source of sulfur to the stratosphere background aerosols ${ }^{1,2}$. Based on the range of expected fractionation for COS oxidation at the tropopause and the stratosphere $\left(\varepsilon_{\mathrm{x}}=-8 \%\right.$ o to $-2.3 \%{ }^{22}$ ), and the atmospheric $\delta^{34} S$ value we measured, the COS oxidation products (which end up as stratospheric aerosols $)$ are expected to have an isotopic value of $4.9-10.6 \%$ o $\left(\delta^{34} S_{\text {products }}=\delta^{34} S_{\mathrm{COS}}+\varepsilon_{\mathrm{x}}\right)$. Given the measured $\delta^{34} S$ of stratospheric background aerosols ${ }^{23}$ of $2.6 \%$, our COS isotopic measurements are consistent with COS being an important, but not the single, source for these aerosols.

It is also possible to constrain the relative contribution of the ocean and anthropogenic COS sources, by a simple 1-box isotopic balance model as illustrated in Fig. 3. For this model we use the following initial assumptions regarding the isotopic signatures of COS sources and sinks.

Ocean source: We assume here that the isotopic composition of COS emitted from the ocean is $\sim 19 \%$, with negligible fractionation during degassing, similar to the values recently found for another oceanic trace sulfur 


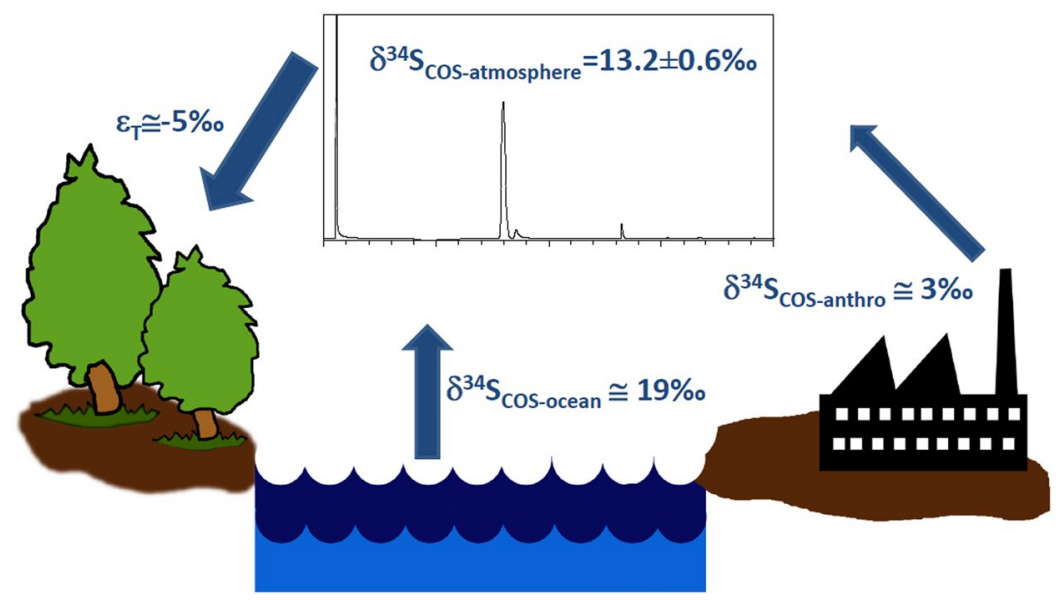

Figure 3. A scheme illustrating the isotopic mass balance for atmospheric COS, assuming values for anthropogenic emissions $\left(\delta^{34} \mathrm{~S}_{\text {COS-anthro }}\right)$, for ocean emissions $\left(\delta^{34} \mathrm{~S}_{\text {COS-ocean }}\right)$, and for fractionation during (plant dominated) uptake $\left(\varepsilon_{\mathrm{T}}\right)$. Using the $\operatorname{COS} \delta^{34} \mathrm{~S}$ value we measured in the atmosphere (appears in a GC/ MC-ICPMS chromatogram) it is estimated by Equation 2 that $\sim 48 \%$ of COS emissions originate in the ocean. (Images drawn by Ayelet Angert).

compound - DMS ${ }^{24}$. This assumption is feasible since both COS and DMS are degradation products of organic sulfur. Organic sulfur of marine microorganisms is produced by microbial assimilatory sulfate reduction process from seawater sulfate $\left(+21.1 \%\right.$ ) with a small $(<3 \%)$ fractionation ${ }^{25}$, similar to that found for DMSP/DMS ${ }^{24,26,27}$. Moreover, part of the oceanic flux of the COS is the result of oxidation of DMS to $\mathrm{COS}^{14}$, and if no fractionation is involved in the oxidation then the DMS and COS are expected to have similar $\delta^{34} S$ value.

Anthropogenic source: The $\delta^{34} \mathrm{~S}$ values of sulfate and sulfur dioxide related to fossil fuel combustion and vehicle exhausts are reported to be in the range of $+4 \%$ o to $+8 \%$, while refineries in Washington, USA and Michigan, USA were found to have a $\delta^{34} S$ value of $-1.6 \%$ and $+2 \%$ to $+4 \%$ respectively ${ }^{28}$. Sulfate aerosols above heavily industrialized areas in northern America and Europe were found ${ }^{29-31}$ to have $\delta^{34}$ S values between $3 \%$ o to $9 \%$. According to the values above, it is estimated ${ }^{28}$ that anthropogenic sulfate have average $\delta^{34} S$ value of $3 \pm 2 \%{ }^{28}$. If $\mathrm{COS}$ is released to the atmosphere from its anthropogenic sources with no fractionation or a very small one, then we can assume similar $\operatorname{COS} \delta^{34} S$ values as reflected in sulfate aerosols of industrial sulfate $(\sim 3 \%)$.

Plant uptake: Previous studies ${ }^{32,33}$ have shown that most of the COS that diffuses into plant leaves is hydrolyzed immediately, and that the back-diffusion is negligible. In such case, the overall fractionation of plant uptake is that of the fractionation in diffusion, and possible fractionation during enzyme-mediated fractionation will have no effect. We calculate that the expected fractionation in binary diffusion of COS in $\mathrm{N}_{2}$, according to the theory of binary diffusion of gases ${ }^{34}$, is $\sim-5 \%$.

Atmospheric oxidation, and soil uptake: The overall fractionation in all atmospheric oxidation processes is estimated to be relatively small, $-8 \%$ in the tropopause and lower in the stratosphere ${ }^{22}$. It is also estimated that less than $10 \%$ of the COS transported to the stratosphere is consumed there, while the rest returns to the troposphere $^{1}$. The fractionation in uptake by few soil bacteria genera was found to be in the range of $-2 \%$ to $-4 \%$, and genus dependent ${ }^{35}$.

Since the rates of soil uptake and atmospheric oxidation are small relative to plant uptake, and since the fractionations in these processes are not well constrained, we will simplify Equation 1 by pooling together all the sinks with one overall fractionation $\left(\varepsilon_{\mathrm{T}}\right)$ that will be assumed to be $-5 \%$. Assuming mass balance we get:

$$
\mathrm{O} / \mathrm{A}=-\left(\delta^{34} \mathrm{~S}_{\mathrm{COS}-\text { anthropogenic }}-\delta^{34} \mathrm{~S}_{\mathrm{COS} \text {-atmosphere }}-\varepsilon_{\mathrm{T}}\right) /\left(\delta^{34} \mathrm{~S}_{\text {COS-ocean }}-\delta^{34} \mathrm{~S}_{\text {COS-atmosphere }}-\varepsilon_{\mathrm{T}}\right),
$$

where $\mathrm{O} / \mathrm{A}$ is the ratio between the ocean and anthropogenic sources.

Using our own measured $\delta^{34} S$ value for Jerusalem and the Canary Islands of $13.2 \%$, it is estimated (Fig. 3 ) that about half of the atmospheric COS (48\%) comes from the ocean, while the rest is contributed by anthropogenic emissions. This initial estimate (based on our measurements) is indeed in broad agreement with previous estimates ${ }^{4,5,14}$. In contrast, using the only previously published measurement of atmospheric $\operatorname{COS} \delta^{34} \mathrm{~S}$ of $4.9 \pm 0.3 \%{ }^{15}$ gives an $\mathrm{O} / \mathrm{A}$ ratio of $16 \%$ (i.e. $84 \%$ of the COS source is anthropogenic), which is far from all current estimates.

The discussion above and the simple model calculations we made show that the isotopic approach for COS sources attribution is feasible and promising. However, it is possible that deviations for the simplifying assumptions above are non-negligible. To improve this approach, there is a need for direct measurements of the sources and sinks isotopic signatures, and a full scale atmospheric sampling plan to reveal variations in both space (e.g. down-wind of major rayon production areas) and time (e.g. increase in $\delta^{34} S$ resulting from summer photosynthetic drawdown). Results from such measurements could be then analyzed by a transport model, that will allow to separate the contributions of the different sources. 


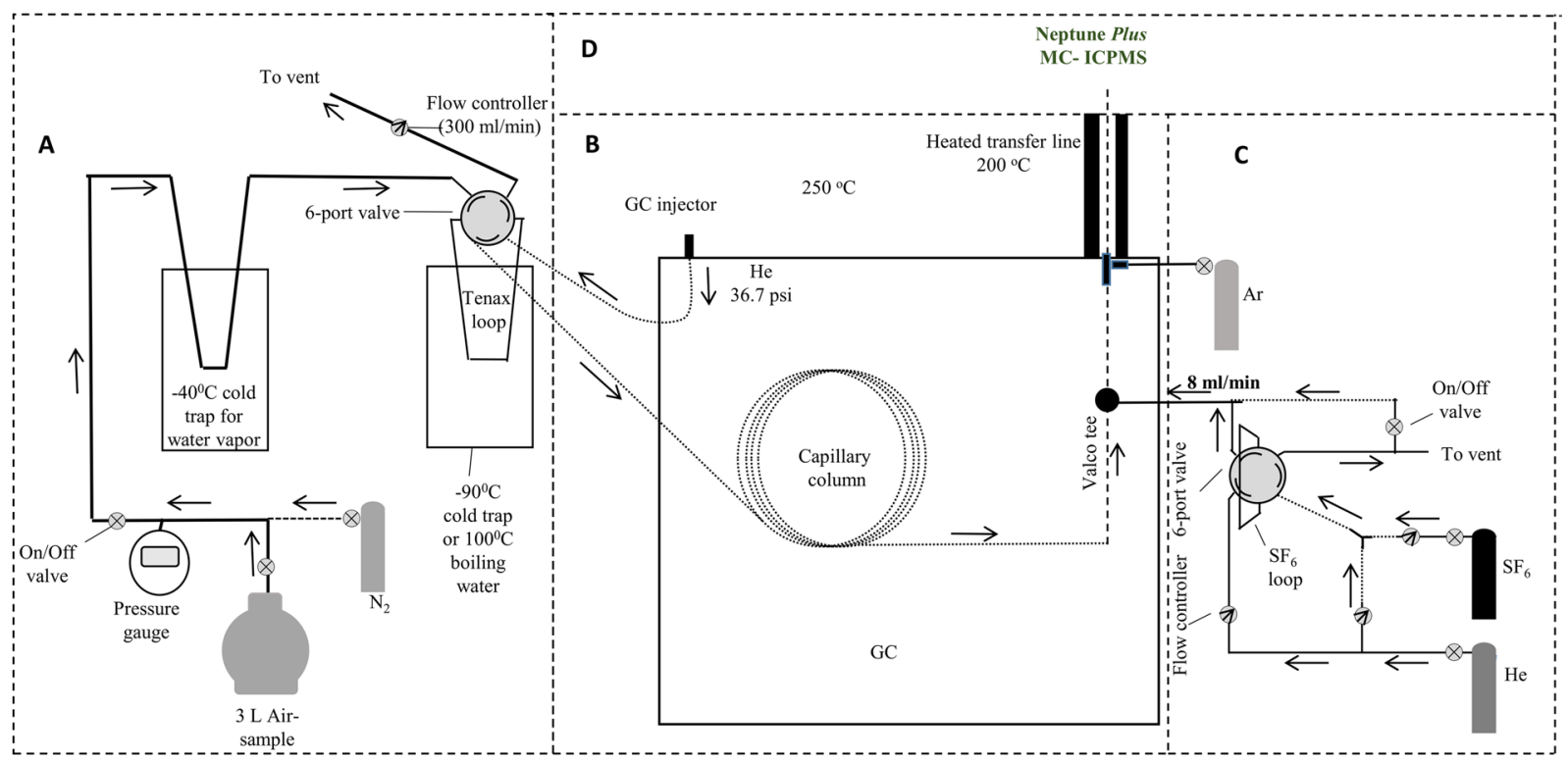

Figure 4. Schematic layout of the analytical system: (A) COS pre-concentration system, (B) gas chromatograph (GC), (C) $\mathrm{SF}_{6}$ standard injection system, (D) The Neptune plus multi-collector inductively coupled plasma mass spectrometry (MC-ICPMS) system.

\section{Methods}

Air sampling and trapping. Two slightly different methods were used. In the initial method (samples from August and October 2017) we used evacuated 2.25 L Sulfinert treated stainless steel cylinder (High Pressure Sample Cylinder, Restek) for air sampling. The cylinders were equipped with two Swagelok valves, one on each side. In order to clean the cylinders, we heated them to $60^{\circ} \mathrm{C}$ with a constant $\mathrm{He}(99.995 \%)$ flow of $100 \mathrm{ml} \mathrm{min}^{-1}$ for several hours. Before air sampling the He in the canisters was analyzed to make sure that the background of absorbed COS in the canister is not larger than 2 pmol. For $\delta^{34} S$ analysis of air in the canisters, we used a constant He flow of $100 \mathrm{ml} \mathrm{min}^{-1}$ for 30 minutes through the cylinder and into the pre-concentration system, described below in this section. In this preliminary method we did not accurately estimate the percent of the air sample that was extracted from the cylinder and therefore we did not present concentrations for this analysis. In the Updated Method (February and March 2018), instead of the 2.25 L sample cylinder, we used much lighter electropolished stainless steel $3 \mathrm{~L}$ canisters (To-can, Restek), which allow easier shipping. Previous work ${ }^{7}$ have shown that COS is stable over weeks during storage in such stainless-steel electropolished canisters, even if water-vapor is present. Hence, water vapor was not removed during sampling. We also added a pressure gauge $(0.25 \%$ precision, Ashcroft) for accurate measurement of air sample extraction. In order to clean these canisters, they were vacuumed to a pressure of $\sim 2 \mathrm{Kpa}$ and then filled with $\mathrm{N}_{2}(99.99 \%$, pre-checked to be COS free) up to $92 \mathrm{Kpa}$, before adding $2 \mathrm{ml}$ of purified water. The canisters were then pumped down to $\sim 30 \mathrm{Kpa}$ and heated to $120^{\circ} \mathrm{C}$ for 1 hour. Then they ware vacuumed and filled with $\mathrm{N}_{2}$ repeatedly 10 times. Before air sampling, the $\mathrm{N}_{2}$ in the canisters was measured to make sure that the background of absorbed COS in the canister is not larger than 2 pmol ( $\sim 5 \%$ of typical atmospheric COS sample). The error that these blanks can introduce is less than $0.6 \%$, based on the blanks isotopic composition. After air sampling, the canisters were pressurized with $\mathrm{N}_{2}$ (99.99) to $350 \mathrm{Kpa}$, and this pressure was utilized to extract $67 \%(\sim 2 \mathrm{~L})$ of the air sample into the pre-concertation system (Fig. $4 \mathrm{~A})$. This system, which is similar but simpler than that used by Hattori ${ }^{15}$, collects the COS from the gas stream by a $1.59 \mathrm{~mm}$ (ID) $\times 3.18 \mathrm{~mm}$ (OD) Teflon tube trap filled with $50 \mathrm{mg}$ Tenax (TA, 60-80 mesh; Sigma-Alorich (MO, USA) cooled by ethanol at $-90^{\circ} \mathrm{C}$. A flow controller keeps the flow below $300 \mathrm{ml} \mathrm{min}^{-1}$. Before the Tenax trap, a cold trap cooled by ethanol at $-40^{\circ} \mathrm{C}$ is used to remove water vapor. The Tenax trap is connected through a six-way valve to a GC. After $65 \mathrm{~min}$ (with decreasing flow rates), the pressure in the cylinder dropped down to $\sim 115 \mathrm{Kpa}$. The Tenax trap is then warmed by hot (boiling) water to $\sim 100^{\circ} \mathrm{C}$, and the six-way valve is used to inject the sample to the GC. In contrast to Hattori et al. ${ }^{15}$ no pre-concentration in liquid $\mathrm{N}_{2}$ trap before the GC was needed.

Instrumentation. The system employed for the S-isotope analysis of COS consisted of a gas chromatograph (GC, Trace 2000 series, Thermo, Germany) coupled with a Neptune Plus ${ }^{\mathrm{TM}}$ MC-ICPMS (Thermo Scientific, Bremen, Germany) as described in Fig. 4. The GC was equipped with a split/splitless injector for direct injection of volatile samples and a heated $\left(70^{\circ} \mathrm{C}\right)$ six-way valve gas inlet system (Valco Instrument Co, TX, USA) for the introduction of gaseous compounds with a computer-controlled actuator. The GC column $(60 \mathrm{~m} * 0.320 \mathrm{~mm}$, GS-GASPRO, Agilent Technologies) is able to separate cleanly between $\mathrm{SO}_{2}$ or $\mathrm{CS}_{2}$ and COS. A transfer line, heated to $200^{\circ} \mathrm{C}$, connected the GC to the plasma source ${ }^{18}$.

The $\mathrm{S}$ species were then atomized and ionized in the plasma source and yielded ${ }^{32} \mathrm{~S}^{+}$and ${ }^{34} \mathrm{~S}^{+}$ions that were transferred to the mass spectrometer unit of the GC/MC-ICPMS system for isotope ratio analysis. The Neptune 
MC-ICPMS system is a double-focusing magnetic-sector instrument equipped with eight moveable Faraday detectors and one fixed detector for simultaneous detection of different masses. The Faraday detectors were positioned to simultaneously collect ${ }^{32} \mathrm{~S}^{+}$and ${ }^{34} \mathrm{~S}^{+}$. Table 1 presents the operational conditions of the GC-MC-ICPMS system. Data processing procedure was as described in detail elsewhere ${ }^{16,18}$.

Reagents and standards. $\quad$ DMS ( $>99 \%)$, Thiophene $(99+\%)$ and carbon disulfide $\left(\mathrm{CS}_{2}\right.$, anhydrous $\left.\geq 99 \%\right)$ were purchased from Sigma-Aldrich (MO, USA). Sulfur hexafluoride (SF6, $500 \mathrm{ppm}$ in helium) was purchased from Praxair (PA, USA). A standard for S compounds in He, 21ppm (20.8 ppm COS, 20.5 ppm $\mathrm{CS}_{2}, 20.9 \mathrm{ppm}$ DMS, $20.9 \mathrm{ppm}$ Ethyl thiol, $20.7 \mathrm{ppm} \mathrm{H}_{2} \mathrm{~S}, 20.8 \mathrm{ppm}$ Methyl thiol) was purchased from Air Liquide America (PA, USA) ("Mix 1"). A COS gas mixture (4.7\%) in helium as balance gas ("Mix 2") was purchased from Air Liquide America. The sulfur isotope reference materials NBS-127 (BaSO4; $\left.\delta^{34} \mathrm{~S}=21.1 \% 0\right)$, IAEA-S- $1\left(\mathrm{Ag}_{2} \mathrm{~S} ;-0.3 \%\right.$ ), and IAEA-SO-6 $\left(\mathrm{BaSO}_{4} ;-34.1 \%\right.$ ) were purchased from the National Institute of Standards and Technology (NIST, USA) and were used for calibration of all the in-house standards.

The $\delta^{34} S$ values of Mix 1 were calibrated against in-house liquid standards DMS $\left(-3.0 \pm 0.1 \%\right.$ ), $\mathrm{CS}_{2}$ $(17.2 \pm 0.1 \%$ ) and Thiophene $(9.6 \pm 0.2 \%$ ) ("Mix 5 ") that were pre-calibrated against international standards (using elemental analyzer isotope ratio ${ }^{16,18}$. These standards, diluted in toluene to form $\sim 81 \mathrm{pmol} \mu \mathrm{L}^{-1}$, were injected directly in to the GC injector $\left(1 \mu \mathrm{l}\right.$, split $5, \sim 16 \mathrm{pmol}$ on column) as detailed in Said-Ahmad et al. ${ }^{18}$. Then, in each day of analysis (COS standards of air) both Mix 1 and Mix 5 were injected to calibrate the internal standard $\mathrm{SF}_{6}$. All the $\delta^{34} \mathrm{~S}$ values in this work are reported against VCDT.

\section{Data Availability}

All data generated or analysed during this study are included in this published article.

\section{References}

1. Chin, M. \& Davis, D. A reanalysis of carbonyl sulfide as a source of stratospheric background sulfur aerosol. Journal of Geophysical Research: Atmospheres 100, 8993-9005 (1995).

2. Crutzen, P. J. The possible importance of CSO for the sulfate layer of the stratosphere. Geophysical Research Letters 3, 73-76 (1976).

3. Hanson, D. R., Ravishankara, A. \& Solomon, S. Heterogeneous reactions in sulfuric acid aerosols: A framework for model calculations. Journal of Geophysical Research: Atmospheres 99, 3615-3629 (1994).

4. Berry, J. et al. A coupled model of the global cycles of carbonyl sulfide and $\mathrm{CO}_{2}$ : A possible new window on the carbon cycle. Journal of Geophysical Research: Biogeosciences 118, 842-852 (2013).

5. Campbell, J. et al. Large historical growth in global terrestrial gross primary production. Nature 544, 84-87 (2017).

6. Campbell, J. et al. Photosynthetic control of atmospheric carbonyl sulfide during the growing season. Science 322, 1085-1088 (2008).

7. Montzka, S. et al. On the global distribution, seasonality, and budget of atmospheric carbonyl sulfide (COS) and some similarities to $\mathrm{CO}_{2}$. Journal of Geophysical Research: Atmospheres 112 (2007).

8. Hilton, T. W. et al. Peak growing season gross uptake of carbon in North America is largest in the Midwest USA. Nature Clim. Change 7, 450-454 (2017).

9. Kieber, D. J., Jiao, J., Kiene, R. P. \& Bates, T. S. Impact of dimethylsulfide photochemistry on methyl sulfur cycling in the equatorial Pacific Ocean. Journal of Geophysical Research: Oceans 101, 3715-3722 (1996).

10. Campbell, J. et al. Atmospheric carbonyl sulfide sources from anthropogenic activity: Implications for carbon cycle constraints. Geophysical research letters 42, 3004-3010 (2015).

11. Zumkehr, A., Hilton, T. W., Whelan, M., Smith, S. \& Campbell, J. E. Gridded anthropogenic emissions inventory and atmospheric transport of carbonyl sulfide in the US. Journal of Geophysical Research: Atmospheres 122, 2169-2178 (2017).

12. Whelan, M. E. et al. Reviews and syntheses: Carbonyl sulfide as a multi-scale tracer for carbon and water cycles. Biogeosciences $\mathbf{1 5}$, 3625-3657 (2018).

13. Launois, T., Belviso, S., Bopp, L., Fichot, C. \& Peylin, P. A new model for the global biogeochemical cycle of carbonyl sulfide-Part 1: Assessment of direct marine emissions with an oceanic general circulation and biogeochemistry model. Atmospheric Chemistry and Physics 15, 2295-2312 (2015).

14. Kettle, A. J., Kuhn, U., von Hobe, M., Kesselmeier, J. \& Andreae, M. O. Global budget of atmospheric carbonyl sulfide: Temporal and spatial variations of the dominant sources and sinks. Journal of Geophysical Research: Atmospheres 107, ACH 25-21-ACH25-16 (2002).

15. Hattori, S. et al. Determination of the sulfur ssotope ratio in carbonyl sulfide using gas chromatography/isotope ratio mass spectrometry on fragment ions 32S+, 33S+, and 34S+. Analytical Chemistry 87, 477-484 (2015).

16. Amrani, A., Sessions, A. L. \& Adkins, J. F. Compound-specific $\delta 34$ S analysis of volatile organics by coupled GC/multicollectorICPMS. Analytical Chemistry 81, 9027-9034 (2009).

17. Said-Ahmad, W. \& Amrani, A. A sensitive method for the sulfur isotope analysis of dimethyl sulfide and dimethylsulfoniopropionate in seawater. Rapid Communications in Mass Spectrometry 27, 2789-2796 (2013).

18. Said-Ahmad, W. et al. Compound-specific sulfur isotope analysis of petroleum gases. Analytical chemistry 89, 3199-3207 (2017).

19. Inomata, Y., Matsunaga, K., Murai, Y., Osada, K. \& Iwasaka, Y. Simultaneous measurement of volatile sulfur compounds using ascorbic acid for oxidant removal and gas chromatography-flame photometric detection. Journal of Chromatography A 864, 111-119 (1999)

20. Stein, A. et al. NOAA's HYSPLIT atmospheric transport and dispersion modeling system. Bulletin of the American Meteorological Society 96, 2059-2077 (2015).

21. Newman, L., Krouse, H. R. \& Grinenko, V. A. Sulphur isotope variations in the atmosphere in Stable Isotopes: Natural and anthropogenic sulphur in the environment SCOPE (eds. H.R. Krouse \& V.A. Grinenko) (John Wiley \& Sons, 1991).

22. Schmidt, J. A. et al. OCS photolytic isotope effects from first principles: sulfur and carbon isotopes, temperature dependence and implications for the stratosphere. Atmospheric Chemistry and Physics 13, 1511-1520 (2013).

23. Castleman, A. Jr., Munkelwitz, H. \& Manowitz, B. Isotopic studies of the sulfur component of the stratospheric aerosol layer. Tellus 26, 222-234 (1974).

24. Amrani, A., Said-Ahmad, W., Shaked, Y. \& Kiene, R. P. Sulfur isotope homogeneity of oceanic DMSP and DMS. Proceedings of the National Academy of Sciences 110, 18413-18418 (2013).

25. Kaplan, I. \& Rittenberg, S. Microbiological fractionation of sulphur isotopes. Microbiology 34, 195-212 (1964).

26. Gutierrez-Rodriguez, A. et al. Dimethylated sulfur compounds in symbiotic protists: A potentially significant source for marine DMS (P). Limnology and Oceanography 62, 1139-1154 (2017).

27. Oduro, H., Van Alstyne, K. L. \& Farquhar, J. Sulfur isotope variability of oceanic DMSP generation and its contributions to marine biogenic sulfur emissions. Proceedings of the National Academy of Sciences 109, 9012-9016 (2012). 
28. Norman, A.-L. et al. Aerosol sulphate and its oxidation on the Pacific NW coast: S and O isotopes in PM2. 5. Atmospheric Environment 40, 2676-2689 (2006).

29. McArdle, N. C. \& Liss, P. S. Isotopes and atmospheric sulphur. Atmospheric Environment 29, 2553-2556 (1995).

30. Norman, A. et al. Sources of aerosol sulphate at Alert: Apportionment using stable isotopes. Journal of Geophysical Research 104, 11,619-11,632 (1999).

31. Wadleigh, M. A., Schwarcz, H. P. \& Kramer, J. R. Areal distribution of sulphur and oxygen isotopes in sulphate of rain over eastern North America. Journal of Geophysical Research: Atmospheres 106, 20883-20895 (2001).

32. Sandoval-Soto, L., Kesselmeier, M., Schmitt, V., Wild, A. \& Kesselmeier, J. Observations of the uptake of carbonyl sulfide (COS) by trees under elevated atmospheric carbon dioxide concentrations. Biogeosciences 9, 2935-2945 (2012).

33. Stimler, K., Nelson, D. \& Yakir, D. High precision measurements of atmospheric concentrations and plant exchange rates of carbonyl sulfide using mid-IR quantum cascade laser. Global change biology 16, 2496-2503 (2010).

34. Mason, E. \& Marrero, T. The diffusion of atoms and molecules in Advances in Atomic and Molecular Physics Vol. 6 155-232 (Elsevier, 1970).

35. Kamezaki, K. et al. Sulfur isotopic fractionation of carbonyl sulfide during degradation by soil bacteria. Environmental Science \& Technology 50, 3537-3544 (2016).

\section{Acknowledgements}

The authors thank the NOAA Air Resources Laboratory (ARL) for the provision of the HYSPLIT transport and dispersion model used in this publication.

\section{Author Contributions}

A. Angert and A. Amrani designed the research and wrote the main manuscript text. W.S.A. prepared Figure 1, C.D. and W.S.A. prepared Figure 4, and W.S.A., C.D. A. Amrani and A. Angert did the experimental work.

\section{Additional Information}

Competing Interests: The authors declare no competing interests.

Publisher's note: Springer Nature remains neutral with regard to jurisdictional claims in published maps and institutional affiliations.

(c) (i) Open Access This article is licensed under a Creative Commons Attribution 4.0 International

License, which permits use, sharing, adaptation, distribution and reproduction in any medium or format, as long as you give appropriate credit to the original author(s) and the source, provide a link to the Creative Commons license, and indicate if changes were made. The images or other third party material in this article are included in the article's Creative Commons license, unless indicated otherwise in a credit line to the material. If material is not included in the article's Creative Commons license and your intended use is not permitted by statutory regulation or exceeds the permitted use, you will need to obtain permission directly from the copyright holder. To view a copy of this license, visit http://creativecommons.org/licenses/by/4.0/.

(C) The Author(s) 2019 